\title{
АДМИНИСТРАТИВНОЕ ПРАВО
}

DOI: $10.14529 /$ pro-prava200520

УДК $341.232 .3+341.232 .4$

ПП № 5(79)-2020. с. $111-115$

Пустовалов Е.В.

АДМИНИСТРАТИВНОЕ СОТРУДНИЧЕСТВО КОМПЕТЕНТНЫХ ОРГАНОВ ПРИ ФУНКЦИОНИРОВАНИИ ЕДИНОГО РЫНКА УСЛУГ ЕАЗС'

Pustovalov E.v.

ADMINISTRATIVE COOPERATION

OF COMPETENT AUTHORITIES

IN THE FUNCTIONING OF THE SINGLE MARKET OF SERVICES OF THE EAEU

В статье рассматривается формирование и функционирование единых рынков товаров, услуг, капитала и трудовых ресурсов ЕАЭС с акцентом на едином рынке услуг. Анализируется содержание режима единого рынка услуг, условия его функционирования. Рассматриваются вопросы возможности прямого (непосредственного) применения некоторых положений Договора о ЕАЭС по вопросам функционирования единого рынка услуг, а также порядок такого применения. Отмечается, что ряд требований режима единого рынка услуг возможен для реализации только в условиях административного сотрудничества компетентных органов государствчленов Союза, уполномоченных осуществлять регулирование и контроль в соответствующих секторах услуг. Базой для данного сотрудничества являются соглашения об административном сотрудничестве. В связи с этим анализируются характеристики таких соглашений, текущая работа по согласованию их условий, а также иные возможные положения для включения в них, которые выходят за пределы имеющейся концепции.

Ключевые слова: ЕАЭС, единый рынок, Евразийский экономический союз, интеграционное объединение, торговля услугами, административное сотрудничество, компетентный орган.

The article examines the formation and functioning of the single markets of goods, services, capital and labor resources of the EAEU with an emphasis on the single market of services. The content of the single service market regime, the conditions for its functioning are analyzed. The issues of the possibility of direct enforcement of certain provisions of the Treaty on the EAEU on the functioning of the single market of services, as well as the procedure for such enforcement are considered. It is noted that a number of requirements of the single service market regime are possible for implementation only under conditions of administrative cooperation between the competent authorities of the Union member states authorized to exercise regulation and control in the relevant service sectors. The basis for this cooperation is agreements on administrative cooperation. In this regard, the characteristics of such agreements, the current work to agree on their terms, as well as other possible

${ }^{1}$ Статья подготовлена в рамках выполнения государственного задания Минобрнауки России, шифр проекта: 26.12267.2018/12.1 
provisions for inclusion in them, which go beyond the existing concept, are analyzed.

Keywords: EAEU, single market, Eurasian Economic Union, integration association, trade in services, administrative cooperation, competent authority.

Евразийский экономический союз (далее - Союз, ЕАЭС), учрежденный Договором о Евразийском экономическом союзе (подписан в г. Астане 29.05.2014) (далее - Договор о ЕАЭС), одной из основных целей имеет формирование единого рынка товаров, услуг, капитала и трудовых ресурсов в рамках Союза (ст. 4 Договора о ЕАЭС). Эта цель является одновременно и средством достижения других целей Союза: создание условий для стабильного развития экономик государств-членов, повышение конкурентоспособности национальных экономик в условиях глобальной экономики. Данный довод обусловлен тем, что единый рынок, являющийся глубокой формой интеграционного взаимодействия, порождает большой синергетический эффект региональной экономической интеграции [4, с. 28], что создает предпосылки для развития национальных экономик, усиления конкуренции, а значит и для повышения качества производимых товаров и услуг.

При этом, если сравнить единый рынок товаров и единый рынок услуг, то, исходя из опыта интеграционных образований, которые ставили задачу создать единые рынки (в частности, из опыта Европейского Союза), и из оценок специалистов, исследовавших вопрос, цель сформировать единый рынок товаров достигается намного быстрее и надежнее, чем цель сформировать единый рынок услуг. Обусловлено данное обстоятельство тем, что в рамках отдельных секторов услуг существует свое специфическое регулирование, которое создает барьеры [1, р. 4]. Недостаточно просто объявить о функционировании единого рынка услуг в какомлибо секторе - необходимо постоянно поддерживать достаточный уровень гармонизации либо содержательной эквивалентности регулирования со стороны национальных правовых систем, снимать появляющиеся барьеры и ограничения, развивать адекватную контролирующую компоненту рынка услуг в конкретных секторах.

Если обратиться к содержанию правового режима единого рынка услуг ЕАЭС, закрепленного в п. 38 Приложения № 16 к Договору о ЕЭАС, то он представляет собой такое состояние рынка услуг в рамках конкретного сектора, при котором каждое государство-член Союза предоставляет лицам любого другого государства-чле- на, во-первых, право на поставку и получение услуг на условиях национального режима или режима наибольшего благоприятствования без ограничений, изъятий и дополнительных требований; вовторых, право на поставку услуг без дополнительного учреждения в форме юридического лица; в-третьих, право на поставку услуг на основании разрешения на поставку услуг, полученного поставщиком услуг на территории своего государствачлена; в-четвертых, право на признание профессиональной квалификации персонала поставщика услуг.

Первые два ключевых условия функционирования единого рынка услуг: национальный режим либо режим наибольшего благоприятствования и осуществление поставок услуг без дополнительного учреждения юридического лица - можно обеспечить за счет непосредственного (прямого) применения положений Договора о ЕАЭС, который является международным договором и частью правовых систем государств-членов Союза, то есть должен применяться и национальными судами. Такое применение положений международных договоров оценивается как действенный механизм защиты прав субъектов соответствующих отношений [5, с. 175] и не требует дополнительных указаний (актов) со стороны органов интеграционного образования.

Исходя из этого, если какой-либо участник рынка услуг, получающий или поставляющий услуги в секторе, в котором Высшим Евразийским экономическим советом признано функционирование единого рынка услуг (Решение Высшего Евразийского экономического совета от 23.12.2014 № 110 «Об утверждении перечня секторов (подсекторов) услуг, в которых функционирует единый рынок услуг в рамках Евразийского экономического союза»), столкнется, например, с тем, что не обеспечивается национальный режим или требуется регистрация национального юридического лица для осуществления поставок, то он может обратиться к судебной защите своих прав с заявлением о признании действий (бездействия) незаконными или нормативных правовых актов недействующими. В частности, на такой механизм применения положений международных договоров в Российской Федерации указывает Верховный суд в п. 5 Постановления Пленума 
от 10.10.2003 № 5 «О применении судами общей юрисдикции общепризнанных принципов и норм международного права и международных договоров Российской Федерации».

Однако требования режима единого рынка о поставке услуг на основе национального разрешения и о признании квалификации персонала труднее для практической реализации и обеспечения. Так, в случае предъявления в государствечлене поставщиком услуги из другого государства-члена каких-либо разрешений (лицензий, аккредитаций и т.п.), а также документов о квалификации персонала получателю услуги или контролирующему органу возникает необходимость их верификации: предъявлялись ли для их получения такие же требования к поставщику, как предъявляются в государстве поставки услуги, не отозвано ли (не аннулировано ли) разрешение, не применены ли какие-то административные меры, создающие препятствия для поставки услуги (например, административное приостановление деятельности) и т.п. Для этих целей, поскольку нет единого наднационального регулирующего и контролирующего органа, требуется административное сотрудничество компетентных органов.

Надежные связи, высокий уровень кооперации между национальными компетентными органами могут обеспечить систему регулирования и контроля на наднациональном уровне качеством сопоставимым с тем, который мог бы обеспечить единый наднациональный орган с компетенцией, признанной всеми государствами-членами Союза. Без достижения такого уровня административного сотрудничества оно может оказаться формальностью, бессмысленной для функционирования единого рынка услуг в соответствующем секторе.

В соответствии со ст. 67 Договора о ЕАЭС взаимное административное сотрудничество компетентных органов государств-членов является одним из средств либерализации торговли услугами. Содержание такого сотрудничества включает в себя оперативный обмен информацией как в целом по секторам услуг, так и в отношении конкретных участников рынка. Помимо этого оно включает в себя создание механизма предупреждения нарушений поставщиками услуг прав и законных интересов потребителей, добросовестных субъектов рынка, а также общественных (государственных) интересов. Для обеспечения эффективности сотрудничества заключаются соот- ветствующие межведомственные соглашения (ст. 68 Договора о ЕАЭС).

Необходимо отметить, что вопросы заключения соглашений об административном сотрудничестве в соответствии с планами либерализации должны быть решены при выстраивании функционирования единого рынка услуг во всех секторах (Решение Высшего Евразийского экономического совета от 26.12.2016 № 23 «Об утверждении планов либерализации по секторам услуг, указанным в Решении Высшего Евразийского экономического совета от 16 октября 2015 г. № 30»). Созданные рабочие группы при Евразийской экономической комиссии, в которые входят как представители Комиссии, так и представители национальных компетентных органов, согласовывают их окончательные редакции, однако в настоящее время по данным, размещаемым на официальном сайте Комиссии (URL: http:// www.eurasiancommission.org), заключенные соглашения отсутствуют.

Вместе с тем исходя из положений Договора о ЕАЭС можно дать им некоторую характеристику. Во-первых, при возникновении коллизии таких соглашений с Договором о ЕАЭС приоритет останется за последним и, более того, он будет основой для толкования и применения положений соглашений об административном сотрудничестве (п. 3 ст. 6 Договора о ЕАЭС). Это обусловлено также их межведомственным характером. Во-вторых, такие соглашения не должны вводить новые дискриминационные меры в отношении торговли услугами или иным образом усложнять условия допуска к поставкам услуг в условиях единого рынка (ст. 66 Договора о ЕАЭС). Например, недопустимо предусматривать нормы, создающие обязанности для поставщиков услуг проходить какие-то дополнительные регистрационные процедуры при трансграничных поставках, депонировать какие-то средства для обеспечения интересов получателей услуг и тому подобное. В-третьих, поскольку административное сотрудничество является одним из средств либерализации торговли услугами (п. 1 ст. 67 Договора о ЕАЭС), то соглашения об административном сотрудничестве (их применение) должны основываться на принципах оптимизации, упрощения и (или) упразднения избыточного регулирования, достаточности уровня взаимного сотрудничества для эффективного функционирования рынка услуг, последовательности, экономической целесообразности (п. 2 ст. 67 Договора о EAЭC). 
Исходя из одной из версий концепции соглашений об административном сотрудничестве [2] предполагается включать в них положения, определяющие сферу и цель взаимодействия компетентных органов государств-членов, регламенты по обмену информацией, процедуры проведения процессуальных действий в рамках административных дел по запросу (проведение проверок, предоставление документов и т.п.), а также регламентацию проведения совместных контрольных (надзорных) мероприятий.

Однако, учитывая специфику отдельных секторов услуг, возможно, этот типовой подход к определению содержания соглашения об административном сотрудничестве для конкретного сектора может как сужаться, так и расширяться. В частности, если для поставок услуг в каком-либо секторе не требуются разрешения (лицензии, аккредитации и т.п.), то раздел по совместным контрольно-надзорным мероприятиям может быть вообще исключен, а процедура обмена информацией может быть минимально формализована.

Одновременно может быть признано целесообразным включение в соответствующие соглашения положений, которые напрямую не вытекают из ст. 68 Договора о ЕАЭС, однако их присутствие там помогло бы улучшить функционирование единого рынка услуг в соответствующем секторе. Например, если компетентные органы осуществляют какую-то координацию и поддержку участников рынка услуг, то возможна организация такой совместной трансграничной координации в целях реализации более масштабных проектов. Также может быть полезным создание с регламентацией в соглашениях об административном сотрудничестве общих открытых информацион114 ных платформ по раскрытию и обмену информацией. В частности, на них могут быть расположены реестры действующих разрешений. В этом случае получатели услуг смогут сами осуществлять проверку поставщиков и не задействовать компетентные органы.

Кроме того, напрашивается дополнительный акт на уровне ЕАЭС (межгосударственный или межправительственный договор в рамках Союза), который бы конституировал механизм снятия барьеров и ограничений функционированию единого рынка услуг в рамках секторов [3, с. 8]. Некоторые наработки такого механизма можно отметить в проекте соглашения об административном сотрудничестве по рынку услуг НИР (размещен на официальном сайте Евразийской экономической комиссии). Так, там есть возможность у участников единого рынка услуг НИР обратиться в компетентные органы с информацией о существовании барьера или ограничения, а последние обязаны предпринять меры по исследованию вопроса (собрать информацию) и, если наличие препятствия функционированию единого рынка услуг подтверждается, принять необходимые меры по его устранению.

В заключение отметим, что от эффективности административного сотрудничества в рамках отдельных секторов услуг зависит поддержание режима единого рынка услуг. Временные задержки в предоставлении информации, непредоставление информации, отсутствие содействия в обеспечении прав приобретателей будет вести к деградации единого рынка услуг, что приведет к потере доверия, и получатели услуг предпочтут национальных поставщиков, а не трансграничные поставки услуг в рамках ЕАЭС, невзирая, возможно, на их более высокое качество и привлекательные ценовые условия.

\section{Литература}

1. Vincent Aussilloux, Agn s B nassy-Qu r, Clemens Fuest, Guntram Wolff Making the best of the European single market // Bruegel Policy Contribution. № 3. 2017. P. 1-18.

2. Концепция разработки проекта соглашения о взаимодействии по делам об административных правонарушениях и проведении совместных контрольных (надзорных) мероприятий по секторам услуг, находящихся в едином рынке. URL: http://www.eurasiancommission.org/ (доступ осуществлен 12.12.2020). 3. Пустовалов Е.В. Механизмы снятия барьеров и ограничений функционирования единого рынка услуг ЕАЭС // Международное право. 2020. № 1. С. 1-9. 4. Тарасевич С.Б., Полякова И.А. Евразийский экономический союз: проблемы и направления развития экономической интеграции // Вестник Полоцкого государственного университета. Серия D: Экономические и юридические науки. 2017. № 14. C. $27-31$.

5. Шахназаров Б.А. Непосредственное применение правил международных договоров при осуществлении защиты прав субъектов внутригосударственных и трансграничных отношений // Актуальные проблемы российского права. 2020. № 8. C. 174-184. 


\section{References}

1. Vincent Aussilloux, Agn s B nassy-Qu r, Clemens Fuest, Guntram Wolff Making the best of the European single market // Bruegel Policy Contribution. № 3. 2017. P. $1-18$.

2. Koncepcija razrabotki proekta soglashenija o vzaimodejstvii po delam ob administrativnyh pravonarushenijah i provedenii sovmestnyh kontrol'nyh (nadzornyh) meroprijatij po sektoram uslug, nahodjashhihsja v edinom rynke. URL: http://www. eurasiancommission.org/ (dostup osushhestvlen 12.12.2020).

3. Pustovalov E.V. Mehanizmy snjatija bar'erov i ogranichenij funkcionirovanija edinogo rynka uslug EAJeS // Mezhdunarodnoe pravo. 2020. № 1. S. 1-9.

4. Tarasevich S.B., Poljakova I.A. Evrazijskij jekonomicheskij sojuz: problemy i napravlenija razvitija jekonomicheskoj integracii // Vestnik Polockogo gosudarstvennogo universiteta. Serija D: Jekonomicheskie i juridicheskie nauki. 2017. № 14. S. 27-31.

5. Shahnazarov B.A. Neposredstvennoe primenenie pravil mezhdunarodnyh dogovorov pri osushhestvlenii zashhity prav sub'ektov vnutrigosudarstvennyh i transgranichnyh otnoshenij // Aktual'nye problemy rossijskogo prava. 2020. № 8 . S. $174-184$

ПУСТОВАЛОВ Евгений Владимирович, старший преподаватель, кафедра финансового права, Уральский государственный юридический университет. 620034, Россия, Свердловская область, г. Екатеринбург, ул. Колмогорова, 54, каб. 202. E-mail: PustovalovE@gmail.com

PUSTOVALOV Evgeniy Vladimirovich, Senior lecturer, Financial Law, Ural State Law University. 620034, Russia, Sverdlovsk region, Yekaterinburg, Kolmogorova St. 54, of. 202. E-mail: PustovalovE@gmail.com 